Article

\title{
Long-Term Effect of Physical Activity on Internalizing and Externalizing Problems and Life Satisfaction
}

\author{
Sukkyung You ${ }^{1}\left(\mathbb{D}\right.$, Kyulee Shin $^{2, *}$ and Mihye $\mathrm{Kim}^{3}$ \\ 1 College of Education, Hankuk University of Foreign Studies, Seoul 130-791, Korea; skyou@hufs.ac.kr \\ 2 Department of Sports Sciences, Seoul National University of Science \& Technology, Seoul 01811, Korea \\ 3 Department of Kinesiology and Sports Studies, College of Science and Industry Convergence, \\ Ewha Womans University, Seoul 03722, Korea; mihyekim0912@gmail.com \\ * Correspondence: kyuleeshin@seoultech.ac.kr
}

check for updates

Citation: You, S.; Shin, K.; Kim, M. Long-Term Effect of Physical Activity on Internalizing and Externalizing Problems and Life Satisfaction. Sustainability 2021, 13, 2322. https:// doi.org/10.3390/su13042322

Academic Editor: José

Carmelo Adsuar

Received: 17 January 2021

Accepted: 18 February 2021

Published: 20 February 2021

Publisher's Note: MDPI stays neutral with regard to jurisdictional claims in published maps and institutional affiliations.

Copyright: (c) 2021 by the authors. Licensee MDPI, Basel, Switzerland. This article is an open access article distributed under the terms and conditions of the Creative Commons Attribution (CC BY) license (https:/ / creativecommons.org/licenses/by/ $4.0 /)$.

\begin{abstract}
This study examined the long-term effect of physical activity on life satisfaction from a sample of 2092 middle school students (52.5\% male) in South Korea. Structural equation modeling analyses were employed to understand how various factors influence youth life satisfaction. Physical activity during physical education class had a long-term influence on life satisfaction through both internalizing and externalizing problem behaviors as mediating factors. Gender differences were found in the relationships between physical activity and life satisfaction. The current findings imply that encouraging students in early adolescence to actively engage in physical education potentially is a useful educational intervention method. Implications and future directions are discussed.
\end{abstract}

Keywords: physical education; physical activity; exercise; internalizing and externalizing problems; life satisfaction; longitudinal study; adolescents

\section{Introduction}

During adolescence, rapid physical and mental changes, along with pubertal development, are experienced. Adolescents also form self-concepts by developing other social relationships with their peers, which once were centered on parents during this period [1,2]. Meanwhile, adolescents often build a negative body image and experience low body esteem while developing secondary sex characteristics [3,4]. They also face difficulties controlling emotions and desires due to academic pressures, difficulties in peer relationships, and conflicts with parents $[5,6]$.

In general, emotional and behavioral maladjustments during adolescents' developmental period are classified into internalizing and externalizing problems. The internalizing problem is a conflict or a problem in adolescents' inner aspects, including depression, social withdrawal, and physical symptoms. The externalizing problem explains an outward manifestation of negative behaviors, such as aggression, destructive behaviors, and delinquency [7]. Internalizing and externalizing problems are closely related to physical activity. Studies have shown that sports and exercise participation alleviate adolescents' depression, anxiety, and aggression [8,9]. McHale and colleagues [10] reported that middle school-aged students who engage in sports activities showed a lower level of social withdrawal compared with those who do not. Sports activities influence the adolescents' body image [11], physical self-concept [3], and self-esteem [12], thus being a protective factor for internalizing and externalizing problems. Previous studies have reported that Korean teenagers' participation in low-intensity physical activities reduces depression while participation in mid-intensity physical activities increases self-esteem [13]. An increase in frequency and duration in physical education classes resulted in lower suicidal tendencies [14]. In addition, middle school students' participation in physical education classes is closely related to school life satisfaction $[15,16]$. 
As stress, bullying, and resulting suicides grew in the early 2010s, policies were put into place that strengthen middle schools' physical education and after-school programs [17]. The system, infrastructure, and policies for after-school sports have been provided but have not been effective. Most Korean parents would rather have their children focused on academic achievement over physical activities since college admission is highly valued [18]; physical education classes in schools are viewed as a last resort for enhancing students' well-being.

Due to the pressure of college admissions, Korean middle and high schoolers do not spend enough time engaging in physical activities [19]. Students' focus is solely concentrated on maintaining a high grade point average. Most students attend after-school academies and institutes in order to do so [20]. This is in contrast to Western societies in which after-school spots and electives are encouraged [21]. When Koreans enter middle school, the number of their physical education classes decrease. First and second graders have three per week, and third graders have two. This is due to more mandatory academic and elective classes [22]. The number of courses for different subjects can also be adjusted depending on the school principal's decisions [23].

Gender difference is confirmed to be a major factor that influences internalizing and externalizing problems. Female students generally tend to show internalizing problems, whereas externalizing problems tend to be outstanding in male students. For example, female students show a higher level of depression, one of the internalizing problems, while male students show a higher level of aggression, one of the externalizing problems [24,25]. Gender difference is also a significant factor that impacts sports engagement [26]. The influence of sports engagement on internalizing and externalizing problems between female and male students may be different since male students participate in sports activities more frequently and because the meaning and relative significance of sports activities may vary between female and male students [27]. In other words, engaging in physical activities has a positive impact on the adolescent group's internalizing and externalizing problems as a whole. However, its effects may differ depending on gender [28]. Previous studies in Korea showed that especially in co-ed physical education classes in middle schools, girls are less likely to participate because they are body-conscious [29]. In addition, boys tend to be better at sports [30]. Furthermore, students think of physical education classes mostly as free time, while challenging themselves only for a short time [31].

Few longitudinal studies have been conducted on the influence of internalizing and externalizing problems led by sports activities on life satisfaction. There is a need to contribute to the extant research on the relevance between sports activities and internalizing and externalizing problems. The current study aimed to examine the long-term effect of adolescents' gender differences in physical activity on life satisfaction, mediated by problem behaviors using adolescent panel survey data. Based on previous studies, we hypothesized that there is both a direct and indirect effect of physical activity on life satisfaction. Adolescents with a higher amount of physical activity have higher life satisfaction, and adolescents with a lower amount of physical activity have lower life satisfaction. In addition to the direct effects, we hypothesized that physical activity is indirectly related to adolescents via a mediator, problem behaviors.

\section{Materials and Methods}

\subsection{Participants}

The data used in the present study are from the Korean Children and Youth Panel Survey (KCYPS), a six-year longitudinal study of students' school life experiences conducted by the National Youth Policy Institute, with funding from the national government. The survey design includes a clustered, stratified national probability sample of 85 elementary schools. This survey was initially completed in 2010, when all of the students were in their fourth year of elementary school. At that time, the mean age of the participants was 10 years old. Students then re-took the survey every last quarter of the year until 2016. The current study utilized secondary data; therefore, ethical approval is not required. The 
analyses in the current study are based on three years of the data (i.e., the 7th to 9th grades). We used a longitudinal sample of 2092 participants, comprised of $1100(52.5 \%)$ male and $992(47.4 \%)$ female students. There were seven missing values for gender. The participants ranged in age from 12 to 14 years $($ Mean $=13.01$ and $S D($ standard deviation $)=0.82$ ).

\subsection{Measures}

To investigate the long-term effects of physical activity on adolescents' life satisfaction, we utilized a longitudinal data set. Specifically, physical activity was selected from Time 1 (2014), adolescents' problem behavior factors (i.e., internalizing and externalizing problem behaviors) were selected from Time 2 (2015), and outcome variables (i.e., life satisfaction) were selected from Time 3 (2016).

\subsubsection{Internalizing and Externalizing Problem Behaviors}

The presence of internalizing and externalizing problem behaviors was assessed using the Korean Emotional Behavioral Problem scale [32]. This scale contains 14 items. Participants rated how often ( $0=$ not true, $1=$ sometimes true, $2=$ very true) they engaged in internalizing problem behaviors (e.g., feelings are easily hurt) and in externalizing problem behaviors (e.g., hurts animals or people without meaning to). Items were coded so that higher scores indicate more problem behaviors. Good internal consistency coefficients with Korean middle school students were reported (e.g., [18]). For the present sample of students, the scale's internal consistency was acceptable (Cronbach's $\alpha=0.88$ and 0.87 , for internalizing and externalizing problems, respectively).

\subsubsection{Student Life Satisfaction Survey (SLSS)}

The SLSS [33] is a five-item, self-reported measure that assesses students' global life satisfaction in ages $8-18$. This scale contains five items. Students were asked to respond to various appraisal statements (e.g., My life is going well) using a seven-point response scale $(1=$ strongly disagree to 7 = strongly agree). Good internal consistency coefficients with Korean middle school students were reported (e.g., [34]). For the present sample, the internal consistency of the scale was acceptable (Cronbach's a $=0.90)$.

\subsubsection{Physical Activity}

Physical Activity was measured using a questionnaire asking for self-evaluation of one's exercise time to the extent of sweating during physical education class (e.g., [35]). Students answered on a five-point Likert scale for this item $(0=$ not at all, $4=4 \mathrm{~h}$ and more). This questionnaire is used as the National Medical Checkup Questionnaire [36], the International Physical Activity Questionnaire [37], and the Student Physical Activity Measurement Sheet [38]. In general, the survey participants have difficulties distinguishing between medium- and high-intensity physical activities [39]. They may report low-intensity activities as medium-intensity activities and medium-intensity activities as high-intensity activities so that they are not perceived as being sedentary [40]. In this regard, the duration of participating in physical activities entailing exercising to the extent of sweating is measured as medium-intensity [38] and it simultaneously enables the prediction of "activeness" in physical education classes. In other words, the higher the number on this scale, the higher the level of physical activities with medium intensity.

\subsection{Analysis}

Structural equation modeling (SEM) was used to assess the hypothesized structural relationships among latent variables. Two mediational models were tested to compare and derive the best model. Model fit was assessed based on several criteria: non-normed fit index (NNFI; [41]), comparative fit index (CFI; [42]), and root mean square error of approximation (RMSEA; [43]). Values lower than 0.08 for the RMSEA and values close to 0.95 for the NNFI and CFI were used to determine a good-fitting model. All analyses were conducted using Mplus [44]. To test the significance of mediating effects, we used the 
bootstrapping method outlined by Shrout and Bolger [45]. Using Preacher and Hayes' [46] nonparametric bootstrapping approach, we tested whether there was a significant indirect effect from gratitude to prosocial and problem behaviors through social support. This method involves repeated sampling from the data set and estimating the indirect effect in each resampled data set.

\section{Results}

\subsection{Descriptive Statistics}

Descriptive statistics for participants' physical activity by gender are provided in Table 1 . The correlations, mean, and standard deviation of the variables in the study are provided in Table 2.

Table 1. Participants' physical activity by gender.

\begin{tabular}{|c|c|c|}
\hline & Male & Female \\
\hline Physical activity (Time 1) ${ }^{\alpha}$ & 3.68 & 2.92 \\
\hline Physical activity (Time 2) ${ }^{\alpha}$ & 3.64 & 2.90 \\
\hline Physical activity (Time 3) ${ }^{\alpha}$ & 3.58 & 2.69 \\
\hline
\end{tabular}

Table 2. Correlations and descriptive statistics for study variables by gender.

\begin{tabular}{|c|c|c|c|c|}
\hline & $\begin{array}{c}1 \\
\text { Physical Activity }\end{array}$ & $\begin{array}{c}2 \\
\text { Externalizing Problems }\end{array}$ & $\begin{array}{c}3 \\
\text { Internalizing Problems }\end{array}$ & $\begin{array}{c}4 \\
\text { Life Satisfaction }\end{array}$ \\
\hline 1. Physical activity $\alpha$ & 1 & $0.06 *$ & $0.10 *$ & $0.07 *$ \\
\hline 2. Externalizing problems $\alpha$ & 0.07 * & 1 & $0.32 *$ & $0.23 *$ \\
\hline 3. Internalizing problems ${ }^{\alpha}$ & $0.16^{*}$ & $0.35 *$ & 1 & $0.25 *$ \\
\hline 4. Life satisfaction $\alpha$ & $0.15^{*}$ & $0.21 *$ & $0.25 *$ & 1 \\
\hline \multicolumn{5}{|l|}{ Means \pm SD } \\
\hline Male & $3.68(1.17)$ & $1.93(0.55)$ & $2.18(0.74)$ & $3.15(0.61)$ \\
\hline Female & $2.92(1.33)$ & $1.97(0.56)$ & $2.25(0.71)$ & $2.96(0.59)$ \\
\hline
\end{tabular}

Note. Correlations for females are above the diagonal; ${ }^{\alpha}$ Gender difference is significant at ${ }^{*} p<0.05$.

There were significant gender differences in physical activity variables across all three-time points (see Table 1). One-way repeated measures ANOVA was conducted to compare physical activity scores across three time-points for both gender groups. There was a significant effect for time for both gender groups (For males, Wilks Lambda $=0.99$, $F(2,1005)=3.04, p<0.05$; For females, Wilks Lambda $=0.97, F(2,896)=14.93, p<0.05)$. Physical activity decreased over time during the 7th and 9th grade period for both gender groups.

Significant correlations were found among the study variables, in both male and female groups. The Pearson correlation coefficient was used. Gender differences in the study variables were analyzed using $t$-tests. While no significant differences were found in externalizing problems, female students showed a higher level of internalizing problems than males. According to the guidelines of severe non-normality (i.e., skew $>2$; kurtosis $>7$ ) proposed by West, Finch, and Curran [47], the normality assumption for all the variables was met.

\subsection{Testing the Mediational Models}

To assess the plausibility of the hypothesis that students' problem behaviors mediate the relationship between physical activity and life satisfaction, we tested two mediational models. The initial structural model reflecting partial mediation was specified with both direct and indirect paths from physical activity to life satisfaction via mediators. The second structural model represented the full mediational model, which did not include direct effects of physical activity on life satisfaction. Specifically, for the male group, the partial mediational model yielded an overall $\chi^{2}(86)$ value of 498.78 , with CFI $=0.958$, $\mathrm{NNFI}=0.954$, and RMSEA $=0.065$, and the full mediational model yielded an overall 
$\chi^{2}(87)$ value of 507.75, with CFI $=0.937, \mathrm{NNFI}=0.923$, and RMSEA $=0.067$. For the female group, the partial mediational model yielded an overall $\chi^{2}(86)$ value of 151.99 , with $\mathrm{CFI}=0.951, \mathrm{NNFI}=0.934$, and RMSEA $=0.071$, and the full mediational model yielded an overall $\chi^{2}(34)$ value of 281.39 , with CFI $=0.899, \mathrm{NNFI}=0.866$, and RMSEA $=0.130$. A chi-square difference test supported the partial meditational model for the male group and the full meditational model for the female group. Thus, we chose the partial meditational model for the male group and the full meditational model for the female group as the final theoretical models. The standardized parameter estimates for these models are presented in Figure 1.
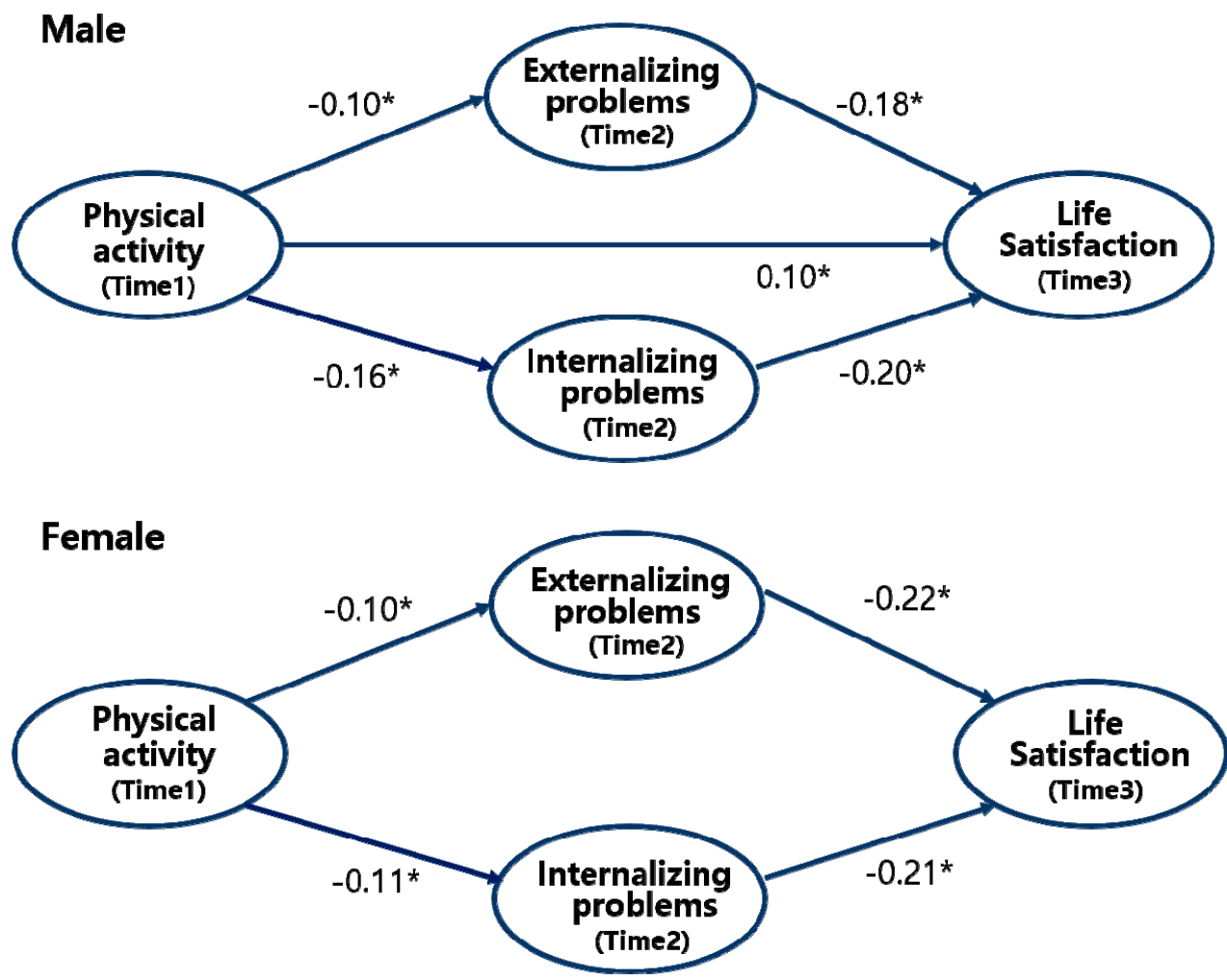

Figure 1. Final model with standardized estimates. Note. ${ }^{*} p<0.05$; significant path coefficients are shown in bold lines.

In regards to the mediating effects, the bootstrap test results indicate that the indirect effects of physical activity on life satisfaction through both internalizing and externalizing problem for females $(\beta=0.02$, and $\beta=0.02, p<0.05$, respectively), and for males $(\beta=0.02$, and $\beta=0.03, p<0.05$, respectively) were all significant.

\section{Discussion}

This study aimed to identify the influence of adolescents' physical activity on problem behaviors and life satisfaction, using nationally representative data. The study's findings show that the level of physical activity engagement and the path model for adjustment vary across gender. First, the current study finding confirmed that physical activity exerted a longitudinal influence on life satisfaction, mediated by middle school-aged students' internalizing and externalizing problems. Internalizing problems refer to emotional maladjustments such as depression and anxiety caused by a negative perception of oneself, the world, and the future [48]. An example would be an individual gripped by fear by exaggerating an event or concern and imagining the worst outcomes [49]. On the other hand, externalizing problems are extrinsic expressions of negative emotions such as aggression, destructive behaviors, and delinquencies. Adolescent externalizing problems are exaggerated by peer pressure. 
This finding implies that the impact of physical activity on internalizing and externalizing problems develops into life satisfaction over time. Previous studies confirmed that physical activity lowers the level of adolescents' depression [12], anxiety [8], stress [50], suicidal ideation [51], and problem behavior [8]. Thereby, the finding of this study supports that physical activity impacts the problem behavior of adolescents. In addition, participating in physical activity during adolescence is reported by previous studies to lead to emotional well-being [52], leisure satisfaction [53], social competence [54], self-esteem [12], and social adjustment [10]. Thus, it implies that positive experiences through physical activities naturally relate to internalizing and externalizing problems such as depression, social withdrawal, aggression, and further enhances life satisfaction.

Second, in the male students, there was an influence of exercising on life satisfaction mediated by internalizing and externalizing problems. That is, physical activity had a direct influence on life satisfaction along with a significant indirect influence through internalizing and externalizing problems. In contrast, female students' cases confirmed a mediated effect of internalizing and externalizing problems on life satisfaction while not showing any direct influence of exercising on life satisfaction. Such results of this study suggest that male students have higher efficacy towards physical activities and that they have more social benefits depending on their level of sports performance than female students $[27,55,56]$. Notably, the survey used in the study included questions such as "the time spent exercising to the extent of sweating during the physical education class." The current study results showed that male students participated more actively in physical activity compared to female counterparts at all time points (i.e., 7 th to 9 th grades). The responses empirically show that male students more actively engage in class than female students. It also implies that male students are more interested in physical activities and are more engaged in sports. Previous studies reported that sports activities are a core issue between peer groups for adolescent boys. In contrast, male students with a higher level of sports performance have high self-worth [57], and boys with such conditions are popular among peers [58]. Such findings from previous studies indicate that the value of physical activities varies depending on gender.

Third, exercising did not directly influence female students' life satisfaction while only mediated through internalizing and externalizing problems. The finding suggests that exercising may not directly affect life satisfaction. Robbins [59] found that there is a difference in perceived benefits of physical activity between female and male students in the age group between sixth and eighth grades (i.e., age 12 and 14). Female students reported that engaging in sports offers the benefits of taking care of oneself, staying in shape, and being healthier. In contrast, male students report that they get to improve or have more athletic skills. Different responses imply that while female students consider sports as a means to maintain health and appearance, male students have desires to improve their athletic abilities. Zullig and White's [60] study also confirmed that adolescent girls' engagement rate in exercise and physical activity shows the sharpest decline in their ages between sixth and ninth grade periods (i.e., age 12 and 15). They suggested that such a result relates to female students' physical activities being less significant in their lives, whereas sports engagement becomes more significant as male students grow up. The current study results showed that both male and female students' physical activity levels decreased from 7th to 9th grades. This trend might reflect the current Korean school climate focusing on college admission. Due to the burden of college admissions, Korean middle and high schoolers do not value physical education, which is not part of the college entrance exam. Meanwhile, the current study finding is in line with the previous study. A recent study [28] using a multi-level growth modeling showed that there are significant gender differences in the long-term relationship between physical activity and problem behaviors. Active physical activity had effects on lessening depression for male students. This indicates that physical activity can play a role as a protective factor for depression for male students. However, female students are more vulnerable to depression; therefore, physical activity alone cannot be a protective factor. Based on these prior studies, it can 
be implied that for female students, though exercising may not have a direct impact on life satisfaction, it may have influence when mediated by internalizing and externalizing problems.

Female students experience pubertal development around the age of eleven. It has been reported that female students' pubertal development influences engagement in physical activities. The earlier they experience puberty development than their peers, they experience maturity fears, which result in less participation in moderate-to-vigorous physical activity [61]. Research with South Korean adolescent girls also reported that more advanced pubertal status is related to lower participation in physical activities [62]. A high volume of studies supports that puberty development negatively impacts girls physical self-perception, engagement rate in sports, and motivation towards physical activity [62-64].

In contrast, pubertal development brings benefits to adolescent boys' sports engagement. This is because male students who used to show a similar level of abilities with female students in athletic skills performance get to develop athletic skills upon puberty and show superior abilities than female students $[65,66]$. In summary, the different impacts of pubertal development on psychological emotions and engagement in physical activities depending on gender differences should be considered. Additionally, to encourage female students' sports engagement, physical activity programs need to be considered so that girls experience fewer body image differences [61]. Sports engagement should be focused on lowering depression and elevating self-efficacy by facilitating positive and enjoyable experiences for both gender groups [62]. To encourage physical education classes, the activities should be enjoyable and meaningful. For example, girls should have access to gender-appropriate equipment and more body-expressive subjects. Students should be able to contribute ideas that they find fulfilling [67], and teachers should be reminded to be open minded and available for questions [68].

\section{Limitations \& Implications}

There are a few limitations of this study. First, demographic and sociological factors (such as household income, bonding between parent and child, parental abuse, contacts with delinquent peers) were not controlled. In future studies, such variables need to be considered. Second, the level of sports engagement was measured by a single scale (the duration of participating in sports). The scale needs to be specified into sub-types such as the types of sports engagement (competitive activities, non-competitive cooperative activities) and degree of sports participation (intensity, frequency) in future studies. Third, there is a need to consider girls' pubertal development when studying sports engagement.

Despite such limitations, the study has various implications: First, the study's findings suggest that exercising reduces the internalizing and externalizing problems of adolescents and may also be the core solution to enhance life satisfaction. Such a result explains the need to develop physical activity programs to address the problem of internalizing and externalizing adolescents' issues in education. Physical activities as a means of educational intervention may improve the quality of life and prevent behavioral problems by developing the protective factor rather than controlling the risk factor of those who have internalizing and externalizing problems based on a positive youth development perspective [69].

Second, the study empirically shows that actively engaging in physical activities during physical education class matters by measuring the effect of exercising to the extent of sweating during sports participation rather than merely measuring the duration of attending physical education class. In fact, in South Korean schools, it is observed that male students enjoy physical activities to the level of sweating a lot, both in and outside of physical education classes. In contrast, many female students gather in groups to talk between peers or watch male students play sports, even during physical education classes [70]. Scholars agree that the extent of such cases is much greater than in other developed countries [71]. Therefore, a gender-based sports education programs should 
be developed to make physical education class an enjoyable time for adolescent females. In Korea, pre-school aged children actively participate in physical activities. However, the participation in physical activity in early childhood differs based on their genders. For example, girls participate in feminine sports such as rhythmic gymnastics. On the other hand, boys tend to participate in traditionally male-centered events such as soccer. The gender stereotypes of masculinity and femininity are reflected in young children's participation in sports, and physical activity and sports participation are recognized as more suitable for boys. Boys are considered to be better in sports activities. Previous studies in the Korean context report that male students are more active and perform better in physical education classes than female students. In the end, girls gradually participate less actively in physical education classes. Critical pedagogies to address gender differences and gender inequities in physical education classes are yet to be applied in Korean schools. One of the current courses' key goals is to help students enjoy an active lifestyle rather than developing function-oriented approaches. Efforts are being made to create and apply programs with exciting elements to prevent students of a specific gender from falling behind in classes.

It is also critical to introduce a national-level sports policy to systematically access physical activity programs suitable for each developmental stage from infancy and childhood. For example, the concept of physical literacy, which the Canadian government introduces, may be facilitated to provide continuous access to physical activity programs suitable for pre-school-aged children, enabling physical, cognitive, and emotional development. By such efforts, children may enjoy physical activities and perceive them as part of their lives. It will also lead to meaningful physical education classes in their school-age and active participation in physical activity throughout the entire life cycle.

Third, the current study participants are students who attend classes taught by physical education teachers with educational responsibility and knowledge, not those who exercise in out-of-school private sports centers. It suggests that the study's findings relate to the value of developing physical education, especially when the context of the study is taken into account. In South Korean society, education is centered on fierce competition for admission to universities and academic performance. The competitive atmosphere is exacerbated, and the chances of having physical education classes decrease as students attend higher grades in schools. Despite the importance of physical activity, sports classes in middle schools in Korea have been extremely limited to 2-3 $\mathrm{h}$ a week because they account for a relatively small portion of college admission examinations. For instance, students in South Korean middle school attend physical education classes four times a week [72], while the number drops to twice a week for the first- and second-year high school students, and once a week for third-year high school students [73]. However, Korean parents do not actively support their children's physical activities since college admission is more valued [18]. In Korean society, physical education classes in schools are the last resort for enhancing students' well-being.

In addition, the problem goes beyond not having enough time assigned to physical education classes and not being able to expect active participation in such activities. Therefore, the results of this longitudinal study, which identified various benefits of active participation in physical activity in physical education classes for school-aged students, could serve as a concrete basis for the improvement of elementary and secondary education curricula in the future.

South Korean students are reported to have shown one of the top ranks in terms of their academic performance among OECD countries [74]. However, their life satisfaction level ranked second to last, and their level of academic pressure was reported to be higher than the average OECD rates [75]. The academic pressure issue and the lowering life quality of adolescents are national issues to be considered [5]. Therefore, the necessity of physical education classes needs to be emphasized, and policy intervention for the development of physical education classes is required. 
In elementary, middle, and high school physical education classes in South Korea, facilitating a fun environment is a significant issue to encourage students' voluntary participation in physical activity, especially for female students. This is quite different from the past Korean physical education classes, where only the acquisition of athletic skills was considered necessary. Therefore, many physical education teachers apply flexible variations of sports products and rules to run courses so that students can have fun and voluntarily participate in classes. By making these efforts, students will be able to enjoy physical activities and perceive their capability to do so, which will lead to meaningful participation in physical education classes. After all, it is clear that such an experience of positive physical activity at a school age will lead to continuous and voluntary participation in physical activity throughout their lives.

Author Contributions: Conceptualization, K.S. and S.Y.; methodology, S.Y.; validation, S.Y.; formal analysis, S.Y.; data curation, K.S.; writing—original draft preparation, S.Y. and M.K.; writing—review and editing, S.Y. and M.K.; supervision, S.Y.; All authors have read and agreed to the published version of the manuscript.

Funding: This work was partially supported by the Hankuk University of Foreign Studies Research Fund.

Institutional Review Board Statement: Ethical review and approval were waived for this study, due to the nature of data is secondary data.

Informed Consent Statement: Informed consent was obtained from all individual participants included in the study.

Data Availability Statement: Data is available upon request at https:/ / www.nypi.re.kr/archive/ mps (accessed date 13 February 2021).

Conflicts of Interest: The authors declare no conflict of interest.

\section{References}

1. Davison, T.E.; McCabe, M.P. Adolescent Body Image and Psychosocial Functioning. J. Soc. Psychol. 2006, 146, 15-30. [CrossRef]

2. Wilkinson, R.B. Best friend attachment versus peer attachment in the prediction of adolescent psychological adjustment. J. Adolesc. 2010, 33, 709-717. [CrossRef]

3. Babic, M.J.; Morgan, P.J.; Plotnikoff, R.C.; Lonsdale, C.; White, R.L.; Lubans, D.R. Physical Activity and Physical Self-Concept in Youth: Systematic Review and Meta-Analysis. Sports Med. 2014, 44, 1589-1601. [CrossRef]

4. You, S.; Shin, K.; Kim, E.K. The Effects of Sociocultural Pressures and Exercise Frequency on the Body Esteem of Adolescent Girls in Korea. J. Child Fam. Stud. 2018, 27, 26-33. [CrossRef]

5. Choi, C.; Lee, J.; Yoo, M.S.; Ko, E. South Korean children's academic achievement and subjective well-being: The mediation of academic stress and the moderation of perceived fairness of parents and teachers. Child Youth Serv. Rev. 2019, 100, 22-30. [CrossRef]

6. Estévez, E.; I Jiménez, T.; Moreno, D. Aggressive behavior in adolescence as a predictor of personal, family, and school adjustment problems. Psicothema 2018, 30, 66-73.

7. Achenbach, T.M.; Ivanova, M.Y.; Rescorla, L.A.; Turner, L.V.; Althoff, R.R. Internalizing/Externalizing Problems: Review and Recommendations for Clinical and Research Applications. J. Am. Acad. Child Adolesc. Psychiatry 2016, 55, 647-656. [CrossRef] [PubMed]

8. Kirkcaldy, B.D.; Shephard, R.J.; Siefen, R.G. The relationship between physical activity and self-image and problem behaviour among adolescents. Soc. Psychiatry Psychiatr. Epidemiol. 2002, 37, 544-550. [CrossRef] [PubMed]

9. McMahon, E.M.; Corcoran, D.P.; O’Regan, G.; Keeley, H.; Cannon, M.; Carli, V.; Wasserman, C.; Hadlaczky, G.; Sarchiapone, M.; Apter, A.; et al. Physical activity in European adolescents and associations with anxiety, depression and well-being. Eur. Child Adolesc. Psychiatry 2017, 26, 111-122. [CrossRef]

10. McHale, J.P.; Vinden, P.G.; Bush, L.; Richer, D.; Shaw, D.; Smith, B. Patterns of personal and social adjustment among sportinvolved and non-involved urban middle-school children. Sociol. Sport J. 2005, 22, 119-136. [CrossRef]

11. Shin, K.; You, S.; Kim, E. Sociocultural pressure, internalization, BMI, exercise, and body dissatisfaction in Korean female college students. J. Health Psychol. 2017, 22, 1712-1720. [CrossRef] [PubMed]

12. Bang, H.; Won, D.; Park, S. School engagement, self-esteem, and depression of adolescents: The role of sport participation and volunteering activity and gender differences. Child. Youth Serv. Rev. 2020, 113, 105012. [CrossRef]

13. Lee, H.G.; Ji, J.C. The relationship of physical activity levels and mental health variables in adolescents. Korean Soc. Sports Sci. 2020, 29, 411-421. [CrossRef] 
14. Oh, Y.A. Relations between mental health and physical activities of middle to high school students. J. Kor. Soc. Sch. Health Educ. 2011, 12, 103-116.

15. Kim, S.Y.; Lee, K.S.; Park, S.I. The effect of physical education class satisfaction on school life satisfaction and the participation in sports in middle school students. Korean Soc. Sports Sci. 2011, 20, 913-923.

16. Valois, R.F.; Zullig, K.J.; Huebner, E.S.; Drane, J.W. Physical Activity Behaviors and Perceived Life Satisfaction Among Public High School Adolescents. J. Sch. Health 2004, 74, 59-65. [CrossRef]

17. Kim, S.K. Relationship between the degree of participation in school sports club, sociality and school violence aggression action among elementary school students. J. Learn. Cent. Curri. Instruct. 2020, 20, 1293-1316.

18. Ryu, D.S.; Kim, B.J. Relationships between parental behavior and children's intrinsic motivation toward physical education. Korean Soc. Sport Psychol. 2010, 21, 85-98.

19. Lee, E.Y.; Lee, K.J. Physical activity, sedentary behaviour and sleep among children and adolescents: Towards an integrative approach to health promotion. Korean Assoc. Health Med. Sociol. 2016, 42, 59-84. [CrossRef]

20. Kim, M.T.; Park, D.W.; Park, J.L. An inquiry into newly-appointed middle school physical education teachers teaching experiences. Educ. Res. 2013, 58, 59-83.

21. Lubans, D.R.; Lonsdale, C.; Cohen, K.; Eather, N.; Beauchamp, M.R.; Morgan, P.J.; Sylvester, B.D.; Smith, J.J. Framework for the design and delivery of organized physical activity sessions for children and adolescents: Rationale and description of the 'SAAFE' teaching principles. Int. J. Behav. Nutr. Phys. Act. 2017, 14, 1-11. [CrossRef] [PubMed]

22. Kim, S.H.; Park, J.J. A case study on operation procedures and obstructive factors of physical activity programs in the free semester in middle schools. J. Educ. Cult. 2019, 25, 575-594.

23. Lee, S.E.; Hong, W.P. Curriculum flexibility in Korean middle school: Current situations and future tasks. J. Curric. Stud. 2020, 38, $5-32$.

24. Card, N.A.; Stucky, B.D.; Sawalani, G.M.; Little, T.D. Direct and Indirect Aggression During Childhood and Adolescence: A Meta-Analytic Review of Gender Differences, Intercorrelations, and Relations to Maladjustment. Child Dev. 2008, 79, 1185-1229. [CrossRef] [PubMed]

25. Ranta, K.; Kaltiala-Heino, R.; Koivisto, A.-M.; Tuomisto, M.T.; Pelkonen, M.; Marttunen, M. Age and gender differences in social anxiety symptoms during adolescence: The Social Phobia Inventory (SPIN) as a measure. Psychiatry Res. 2007, 153, 261-270. [CrossRef] [PubMed]

26. Brown, K.A.; Patel, D.R.; Darmawan, D. Participation in sports in relation to adolescent growth and development. Transl. Pediatr. 2017, 6, 150-159. [CrossRef]

27. Gao, Z.; Lee, A.M.; Harrison, L. Understanding Students' Motivation in Sport and Physical Education: From the Expectancy-Value Model and Self-Efficacy Theory Perspectives. Quest 2008, 60, 236-254. [CrossRef]

28. Lee, T.H.; Lee, S.Y.; Han, Y.S. The moderating effect of gender in the relationship between physical education and adolescents' internalizing and externalizing problem behaviors: Using multi-level growth modeling. Korean J. Cult. Soc. Issues 2015, 21, 131-158.

29. Jeong, H.W.; Jeong, H.C.; Kim, D.J. A case analysis on gender inequality appearing in coed physical education class of middle school. J. Learn. Cent. Curri. Instruct. 2014, 14, 539-558.

30. Park, E.Y.; Kwon, K.N.; Lim, S.W. The practices, problem, and solution of the mixed-gender physical education class in middle School. J. Sport Leis. Stud. 2006, 26, 39-50.

31. Kang, M.W.; Koo, N.H. Prejudice and teaching strategies for girls in physical education classes of middle and high school physical education teachers. Korean J. Sport 2019, 17, 39-48.

32. Cho, B.-H.; Lim, K.-H. Development and validation of emotional or behavioral problems scale. Korean J. Couns. Psychol. 2003, 15, 729-746.

33. Huebner, E.S. Initial development of the student's life satisfaction scale. Sch. Psychol. Int. 1991, 12, 231-240. [CrossRef]

34. Choi, I.S. A study on the relationships with parents, peers, and teachers and life satisfaction among middle school students-An examination of the mediating effect of self-resilience and gender differences. Educ. Sci. Study 2012, 43, 105-129.

35. National Youth Policy Institute. Korean Children and Youth Panel Survey (KCYPS)VIII; National Youth Policy: Sejong, Korea, 2017.

36. National Health Insurance Service. Inquiry of Health Examinations; National Health Insurance Service: Seoul, Korea, 2009.

37. Kim, B.S. Korean Version of International Physical Activity Questionnaire (IPAQ). Korean J. Fam. Med. 2006, 27, $348-357$.

38. Hong, S.Y.; Yang, Y.J.; Park, H.K.; Kim, B.S. Validation of Korean Youth Physical Activity Questionnaire (KYPAQ). Korean J. Phys. Edu. 2006, 45, 161-173.

39. Ainsworth, B.E.; Irwin, M.L.; Addy, C.L.; Whitt, M.C.; Stolarczyk, L.M. Moderate Physical Activity Patterns of Minority Women: The Cross-Cultural Activity Participation Study. J. Women's Health Gend. Based Med. 1999, 8, 805-813. [CrossRef] [PubMed]

40. Courneya, K.S.; Jones, L.W.; Rhodes, R.E.; Blanchard, C.M. Effects of Different Combinations of Intensity Categories on SelfReported Exercise. Res. Q. Exerc. Sport 2004, 75, 429-433. [CrossRef]

41. Bentler, P.M.; Bonett, D.G. Significance tests and goodness of fit in the analysis of covariance structures. Psychol. Bull. 1980, 88 , 588-606. [CrossRef]

42. Bentler, P.M. Comparative fit indexes in structural models. Psychol. Bull. 1990, 107, 238-246. [CrossRef]

43. Steiger, J.H.; Lind, J.C. Statistically based tests for the number of common factors. In Proceedings of the Annual Meeting of the Psychometric Society, Iowa City, IA, USA, May 1980. 
44. Muthén, L.K.; Muthén, B.O. Mplus: User's Guide; Software Manual: Los Angeles, CA, USA, 2006.

45. Shrout, P.E.; Bolger, N. Mediation in experimental and nonexperimental studies: New procedures and recommendations. Psychol. Methods 2002, 7, 422-445. [CrossRef]

46. Preacher, K.J.; Hayes, A.F. SPSS and SAS procedures for estimating indirect effects in simple mediation models. Behav. Res. Methods Instrum. Comput. 2004, 36, 717-731. [CrossRef] [PubMed]

47. West, S.G.; Finch, J.F.; Curran, P.J. Structural equation models with non-normal variables. In Structural Equation Modeling: Concepts, Issues, and Applications; Hoyle, R.H., Ed.; Sage Publish Inc.: Thousand Oaks, CA, USA, 1995; pp. 56-75.

48. Muris, P.; Field, A.P. Distorted cognition and pathological anxiety in children and adolescents. Cogn. Emot. 2008, 22, 395-421. [CrossRef]

49. Tremblay, I.; Sullivan, M.J. Attachment and Pain Outcomes in Adolescents: The Mediating Role of Pain Catastrophizing and Anxiety. J. Pain 2010, 11, 160-171. [CrossRef] [PubMed]

50. Jewett, R.; Sabiston, C.M.; Brunet, J.; O’Loughlin, E.K.; Scarapicchia, T.; O’Loughlin, J. School Sport Participation During Adolescence and Mental Health in Early Adulthood. J. Adolesc. Health 2014, 55, 640-644. [CrossRef] [PubMed]

51. Babiss, L.A.; Gangwisch, J.E. Sports Participation as a Protective Factor Against Depression and Suicidal Ideation in Adolescents as Mediated by Self-Esteem and Social Support. J. Dev. Behav. Pediatr. 2009, 30, 376-384. [CrossRef]

52. Donaldson, S.J.; Ronan, K.R. The effects of sports participation on young adolescents' emotional well-being. Adolescence 2006, 41, 369-389.

53. Shin, K.; You, S. Leisure Type, Leisure Satisfaction and Adolescents' Psychological Wellbeing. J. Pac. Rim Psychol. 2013, 7, 53-62. [CrossRef]

54. Carter, E.W.; Common, E.A.; Sreckovic, M.A.; Huber, H.B.; Bottema-Beutel, K.; Gustafson, J.R.; Dykstra, J.; Hume, K. Promoting Social Competence and Peer Relationships for Adolescents With Autism Spectrum Disorders. Remedial Spéc. Educ. 2013, 35 , 91-101. [CrossRef]

55. Song, K.H. Relationship between grit and achievement behavior in physical education classes based on the expected-value model. J. Korea Converg. Soc. 2019, 10, 429-435.

56. Xiang, P.; McBride, R.; Guan, J.; Solmon, M. Children's motivation in elementary physical education: An expectancy-value model of achievement choice. Res. Q. Exerc. Sport 2003, 74, 25-35. [CrossRef]

57. Piek, J.P.; Baynam, G.B.; Barrett, N.C. The relationship between fine and gross motor ability, self-perceptions and self-worth in children and adolescents. Hum. Mov. Sci. 2006, 25, 65-75. [CrossRef]

58. Shakib, S.; Veliz, P.; Dunbar, M.D.; Sabo, D. Athletics as a Source for Social Status among Youth: Examining Variation by Gender, Race/Ethnicity, and Socioeconomic Status. Sociol. Sport J. 2011, 28, 303-328. [CrossRef]

59. Robbins, L.B.; Sikorskii, A.; Hamel, L.M.; Wu, T.-Y.; Wilbur, J. Gender comparisons of perceived benefits of and barriers to physical activity in middle school youth. Res. Nurs. Health 2009, 32, 163-176. [CrossRef] [PubMed]

60. Zullig, K.J.; White, R.J. Physical Activity, Life Satisfaction, and Self-Rated Health of Middle School Students. Appl. Res. Qual. Life 2010, 6, 277-289. [CrossRef]

61. Davison, K.K.; Werder, J.L.; Trost, S.G.; Baker, B.L.; Birch, L.L. Why are early maturing girls less active? Links between pubertal development, psychological well-being, and physical activity among girls at ages 11 and 13. Soc. Sci. Med. 2007, 64, 2391-2404. [CrossRef] [PubMed]

62. Lee, E.-Y.; An, K.; Jeon, J.Y.; Rodgers, W.M.; Harber, V.J.; Spence, J.C. Biological Maturation and Physical Activity in South Korean Adolescent Girls. Med. Sci. Sports Exerc. 2016, 48, 2454-2461. [CrossRef]

63. Knowles, A.-M.; Niven, A.G.; Fawkner, S.G.; Henretty, J.M. A longitudinal examination of the influence of maturation on physical self-perceptions and the relationship with physical activity in early adolescent girls. J. Adolesc. 2009, 32, 555-566. [CrossRef] [PubMed]

64. Labbrozzi, D.; Robazza, C.; Bertollo, M.; Bucci, I.; Bortoli, L. Pubertal development, physical self-perception, and motivation toward physical activity in girls. J. Adolesc. 2013, 36, 759-765. [CrossRef]

65. Manna, I. Growth Development and Maturity in Children and Adolescent: Relation to Sports and Physical Activity. Am. J. Sports Sci. Med. 2014, 2, 48-50. [CrossRef]

66. Rogol, A.D.; A Clark, P.; Roemmich, J.N. Growth and pubertal development in children and adolescents: Effects of diet and physical activity. Am. J. Clin. Nutr. 2000, 72, 521S-528S. [CrossRef] [PubMed]

67. Kim, N. Daegu Catholic University Exploring Participation Factors for Active Physical Education in Female students. Korean Assoc. Learn. Curric. Instr. 2018, 18, 353-369. [CrossRef]

68. Ham, J.S. Analysis of creative personality factors for PE class flow. J. Learn. Cent. Curri. Instruct. 2015, 15, $139-157$.

69. Caldwell, L.L.; Baldwin, C.K.; Walls, T.; Smith, E. Preliminary Effects of a Leisure Education Program to Promote Healthy Use of Free Time among Middle School Adolescents. J. Leis. Res. 2004, 36, 310-335. [CrossRef]

70. Nam, S.W.; Lee, C.S. Reproduction of gender through physical activities in school. Korean Soc. Social. Sport 2006, 19, 441-458.

71. Korea Institute of Sport Science. A National Report on the Current State of Physical Activity and Improvement Direction among Korean Adolescent Girls; Korea Institute of Sport Science: Seoul, Korea, 2010.

72. Park, H.-R. The Study on the Attitude of Physical Education and Physical Activity Level for Children and Adolescents. J. Korean Soc. Wellness 2016, 11, 195. [CrossRef] 
73. Yu, C.W. Analysis of teacher's perception and organization on physical education elective courses. Korean J. Sport Sci. 2018, 29, 591-602.

74. OECD. PISA 2018 Results (Volume VI): Are Student Ready to Thrive in an Interconnected Word? OECD Publishing: Paris, France, 2018.

75. OECD. PISA 2015 Results (Volume III): Students' Well-Being; OECD Publishing: Paris, France, 2017. 